\title{
Viabilidade econômica do componente arbóreo de sistema agrossilvipastoril comparado ao de plantio florestal na pequena propriedade rural
}

\author{
Caroline Weimann ${ }^{1 *}$, Jorge Antonio de Farias ${ }^{1}$, Gilmar Deponti² \\ ${ }^{1}$ Universidade Federal de Santa Maria, Av. Roraima, 1000, CEP 97105-900, Santa Maria, RS, Brasil \\ ${ }^{2}$ Emater/RS-Ascar, Av. Nossa Senhora da Medianeira, 278/101, CEP 97060-001, Santa Maria, RS, Brasil
}

*Autor correspondente:
carolineweimann@yahoo.com.br

Termos para indexação:

Cultivo contínuo

Custo de produção

Avaliação econômica

Index terms:

Continuous cropping

Production costs

Economic evaluation

Histórico do artigo:

Recebido em 15/02/2016

Aprovado em 14/12/2017

Publicado em 29/12/2017

doi: $10.4336 / 2017 . p f b .37 .92 .1147$

\begin{abstract}
Resumo - O presente trabalho objetivou comparar a viabilidade econômica do componente florestal na pequena propriedade rural, como sistema agrossilvipastoril ou como plantio convencional, no Município de Esperança do Sul, RS. O sistema agrossilvipastoril foi implantado com eucalipto, e o plantio florestal com eucalipto e acácia-negra. Foram utilizados apenas os dados do componente florestal, sendo obtidos por inventário florestal. Os indicadores selecionados para a análise econômico-financeira foram: valor presente líquido (VPL), valor anual equivalente (VAE), taxa interna de retorno (TIR), razão benefício/custo (B/C) e custo médio de produção (CMPr). A taxa de desconto utilizada foi de $7,5 \% \mathrm{ano}^{-1}$. Os dois sistemas de produção foram considerados economicamente viáveis para a rotação de 10 e 15 anos, sendo que a rotação mais longa apresentou maior retorno financeiro. O sistema agrossilvipastoril foi considerado viável, mantendo-se positivo mesmo com taxas de juros mais elevadas. Apesar de o plantio florestal apresentar maior retorno econômico, o sistema agrossilvipastoril apresentou mais vantagens ambientais.
\end{abstract}

\section{Economic viability of trees from agri-silvi-pastoral system compared to tree plantation in a small property}

\begin{abstract}
This study aimed to compare the economic viability of the forestry component from an agri-silvi-pastoral system to tree plantation in a small property in Esperança do Sul municipality, Rio Grande do Sul, State, Brazil. The agri-silvi-pastoral system used only eucalyptus, and the tree plantation was formed using eucalytpus and black wattle. The analysis was carried out using tree component and data were obtained by forest inventory. The indicators selected for economic and financial analysis were: net present value (NPV), equivalent annual value (EAV), internal return rate (IRR), benefit/ cost reason $(\mathrm{B} / \mathrm{C})$ and average cost of production (ACP). The discount rate used was $7.5 \%$ year $^{-1}$. Both systems were considered economically and financially viable, in 10 or 15 years rotation. However, 15 years rotation presented the biggest financial return. Agri-silvi-pastoral system was considered feasible, maintaining positive results even with higher interest rates. Even though the tree plantation presented greater economic returns, the agrisilvipastoral system showed more environmental benefits.
\end{abstract}

\section{Introdução}

O Brasil apresentou, nos últimos anos, uma grande expansão de áreas destinadas à silvicultura. $\mathrm{O}$ eucalipto tem sido utilizado de forma direta e múltipla, para diferentes fins, como lenha, carvão vegetal, varas para a construção civil, movelaria, postes para energia elétrica e mourões para cerca na propriedade rural, ou de forma 
indireta, antes do corte, nos processos de ciclagem de nutrientes, proteção do solo contra erosão, diminuição da pressão de uso de florestas nativas e na geração de sombra para o conforto térmica animal em sistemas agroflorestais, desempenhando papel fundamental para a melhoria da produção animal em pequenas propriedades (Roberto \& Souza, 2011).

O termo agrofloresta é dado para sistemas sustentáveis de uso da terra, os quais envolvem associações de cultivos agrícolas com espécies florestais perenes, cultivados sobre uma mesma unidade de terra. Essa forma de uso permite que as pequenas propriedades rurais se mantenham resilientes, pela diversificação produtiva, que resulta em um sistema produtivo com benefícios econômicos, ambientais e socioculturais (Thevathasan, 2014)

O uso de sistemas integrados com árvores pode trazer maior sustentabilidade ao meio agrícola. Segundo o conceito de sustentabilidade, é necessário que haja equilíbrio entre três grandezas: sociais, econômicas e ambientais. Porém, a que tem mais relevância nas decisões humanas são as relacionadas ao componente econômico (Ferraz, 2003).

Antes de se realizar um investimento é essencial verificar uma série de fatores que podem influenciar o sucesso do negócio. Um dos aspectos mais importantes é a análise financeira do projeto em questão, onde critérios econômicos podem ser utilizados na tomada de decisão. Para essa avalição, deve-se considerar o fluxo de caixa, que consiste em custos e receitas distribuídos do início ao fim do empreendimento, ou seja, ao longo de todo o ciclo do projeto.

Apesar da concordância de que os SAF's apresentam vantagens ecológicas e reduzem o risco de investimento em uma só cultura, é possível constatar que os mesmos representam uma atividade complexa que apresenta tantos riscos e incertezas como outras atividades agrícolas e florestais mais conhecidas, sendo importante avaliar a atividade economicamente, sob condições de risco, para subsidiar os agentes de financiamento, técnicos e produtores nesse tipo de investimento (BentesGama et al., 2005).

Esse trabalho teve por objetivo comparar a viabilidade econômica do componente florestal entre o sistema agrossilvipastoril e plantio florestal na pequena propriedade rural, como alternativa de renda além

Pesq. flor. bras., Colombo, v. 37, n. 92, p. 429-436, out./dez. 2017 de benfeitorias ao meio ambiente, no Município de Esperança do Sul, RS.

\section{Material e métodos}

As áreas em estudo estão localizadas no Município de Nova Esperança do Sul, RS. O clima da região é do tipo "Cfa", em que se caracteriza por apresentar chuva durante todos os meses do ano, temperatura do mês mais quente superior a $22{ }^{\circ} \mathrm{C}$ e a do mês mais frio, entre $-3{ }^{\circ} \mathrm{C}$ e $18^{\circ} \mathrm{C}$ (Moreno, 1961).

Os solos que ocorrerem na região são Argissolo Vermelho Distrófico arênicos, espessarênicos e típicos, podendo apresentar afloramentos rochosos. Solos arênicos e espessarênicos apresentam mudança textural abrupta diferente do típico, onde a mudança é gradual. Geralmente são solos profundos a muito profundos, varia de bem drenados a imperfeitamente drenados. As limitações na drenagem natural ocorrem devidas à mudança textural abrupta ou ao contato lítico direto (rocha). Pode ocorrer rápida infiltração de água no solo, podendo ser acentuado com a mudança textural abrupta, resultando em erosão em sulcos e formação de voçorocas. Ocorrem em relevos desde suave até fortemente ondulados. Esses solos apresentam forte acidez e baixa fertilidade natural, exigindo investimentos em corretivos, fertilizantes e sistemas de manejo, para a obtenção de rendimentos satisfatórios (Streck et al., 2008).

Foram avaliadas áreas de produtores rurais familiares com componente florestal em duas situações: em sistema agrossilvipastoril e em plantio florestal, em duas propriedades, apresentando diferentes idades, arranjos espaciais e condições de sítio (Tabela 1). Vale ressaltar que foram contabilizados apenas os indivíduos de eucaliptos, pois os indivíduos de acácia-negra (Acacia mearnsii) já haviam sido retirados. Os sistemas agrossilvipastoris foram implantados em parceria com a Emater/RS-Ascar, com a inclusão de Eucalyptus grandis como única espécie florestal.

A mensuração florestal foi realizada utilizando-se amostragem sistemática (Loetsch et al., 1973). As parcelas foram alocadas após as árvores de bordadura, sendo distribuídas três parcelas por área. Foram distribuídas paralelamente entre as linhas de plantio e transversalmente nas entrelinhas, tendo cada unidade amostral correspondendo a somente uma linha de plantio (Figura 1). 
Tabela 1. Características do plantio florestal e do componente arbóreo do sistema agrossilvipastoril em pequenas propriedades rurais no município de Nova Esperança do Sul, RS.

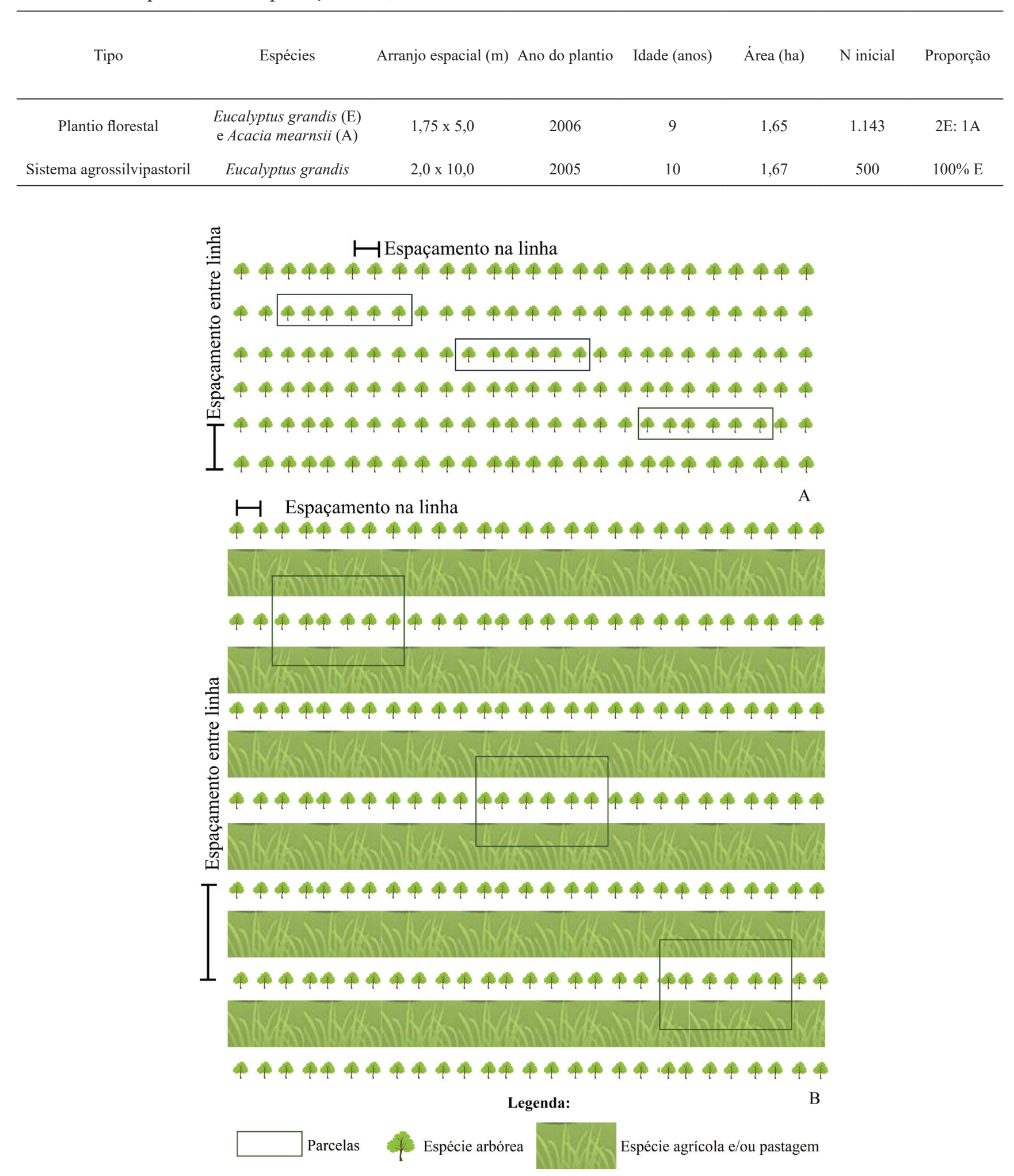

Figura 1. Croqui do plantio convencional e do sistema agrossilvispastotil (B) com a alocação das parcelas. Os espaços em branco no plantio florestal (A), entre os indivíduos de eucalipto, representam o local onde os indivíduos de acácia-negra estavam alocados antes de serem retirados. 
Todas as árvores tiveram o diâmetro a 1,30 m do solo (DAP) medido, usando-se fita métrica $(\mathrm{cm})$. A altura de $50 \%$ das árvores foi medida com hipsômetro digital Vertex $(\mathrm{dm})$.

Para a estimativa da altura das demais árvores, foram utilizados os modelos de Stoffels e de Curtis para o plantio florestal e para o sistema agrossilvipastoril, respectivamente (Tabela 2 ).

$\mathrm{O}$ volume individual das árvores foi calculado pelo produto da área basal, altura medida ou estimada e o fator de forma. $\mathrm{O}$ fator de forma foi determinado pela média da cubagem rigorosa de cinco árvores de cada sistema de produção, fazendo-se a relação entre o volume rigoroso encontrado e o volume do cilindro perfeito. Foi utilizado 0,482 como fator de forma para as árvores no plantio florestal e 0,478 para as do sistema agrossilvipastoril. $\mathrm{O}$ volume de madeira por área foi determinado pelo somatório de volumes individuais nas áreas inventariadas, convertendo-se para 1 ha. Utilizando-se a idade e o volume de cada povoamento, foi possível verificar o incremento médio anual e o incremento individual por ano em cada área.

Os dados referentes à área basal, altura média e volume ha-1 ${ }^{-1}$ número de indivíduos desbastados e remanescentes e incremento médio anual e incremento individual nas áreas de plantio florestal e de sistema agrossilvipastoril estão apresentados na Tabela 3.

Tabela 2. Equações selecionadas para estimar altura de árvores no plantio florestal e no sistema agrossilvipastoril.

\begin{tabular}{cccc}
\hline Equação & Modelo & Autor & Aplicação \\
\hline $\mathbf{1}$ & $\operatorname{lnh}=\mathrm{b}_{0}+\mathrm{b}_{1}$ lnd & Stoffels & Plantio florestal \\
$\mathbf{2}$ & $\operatorname{lnh}=\mathrm{b}_{0}+\mathrm{b}_{1} \cdot \mathrm{d}^{-1}+\mathrm{b}_{2} \cdot \mathrm{d}^{-2}$ & Curtis & $\begin{array}{c}\text { Sistema } \\
\text { agrossilvipastoril }\end{array}$ \\
\hline
\end{tabular}

Em que: $\mathrm{h}=$ altura; $\mathrm{d}=$ diâmetro; $\mathrm{b}_{0}, \mathrm{~b}_{1}, \mathrm{~b}_{2}=$ coeficientes das equações; $\ln$ $=$ logaritmo neperiano.

Tabela 3. Caracterização populacional do plantio convencional e do sistema agrossilvipastoril, em Nova Esperança do Sul, RS.

\begin{tabular}{cccccccccc}
\hline Propriedade & Desbastes & $\mathrm{N}$ & $\overline{\mathrm{g}}$ & $\overline{\mathrm{h}}$ & $\bar{f}$ & $\mathrm{~V}$ & $\mathrm{t}$ & $\mathrm{IMA}$ & Inc. \\
\hline Plantio florestal* & 53 & 709 & 0,0399 & 25,8 & 0,482 & 375,2908 & 9 & 41,6990 & 0,05885 \\
& & & & & & & & & \\
Sistema agrossilvipastoril & 100 & 400 & 0,0550 & 27,7 & 0,478 & 301,4722 & 10 & 30,1472 & 0,07537 \\
\hline
\end{tabular}

Em que: desbastes $=$ número de indivíduos retirados; $\mathrm{N}=$ número de indivíduos remanescentes; $\overline{\mathrm{g}}=$ área basal média $\left(\mathrm{m}^{2}\right) ; \overline{\mathrm{h}}=\mathrm{altura}$ média $(\mathrm{m})$; $\bar{f}=$ fator de forma; $\mathrm{V}=$ volume final $\left(\mathrm{m}^{3} \mathrm{ha}^{-1}\right) ; \mathrm{t}=$ idade do povoamento $($ anos $) ; \mathrm{IMA}=$ incremento médio anual $\left(\mathrm{m}^{3}\right.$ ano $\mathrm{h}^{-1}$ ha $\left.{ }^{-1}\right) ;$ Inc. $=$ incremento individual por ano $\left(\mathrm{m}^{3}\right.$ ano $\left.^{-1}\right)$. ${ }^{*}$ Foram considerados apenas as árvores de eucaliptos.

Para a realização do fluxo de caixa do componente florestal, foi necessário fazer um levantamento dos dados do componente florestal em relação ao custo de implantação, manutenção e venda dos produtos florestais. Para realizar a análise financeira, utilizouse uma taxa de juros de 7,5\% ao ano, adotada (pelo programa Agricultura de Baixa Emissão de Carbono $(\mathrm{ABC})$ através do Banco Nacional de Desenvolvimento Econômico e Social (BNDES, 2015)

Foram considerados para compor os custos de implantação o preparo da área (custo do serviço), insumos (adubo, mudas, formicida, herbicida, inseticida, custo da máquina, entre outros) e mão de obra (aplicação de inseticida e herbicida, plantio, replantio, adubação, controle de formiga, calagem, coroamento), tais custos estão contabilizados por área. Em relação aos custos de manutenção, estes foram estimados em $\mathrm{R} \$ 50,00$ por ano, durante os quatro anos iniciais, para fazer coroamento e desrama. Os custos em relação à colheita florestal não foram contabilizados, pois a floresta foi vendida em pé. Vale ressaltar que a adubação foi realizada apenas no sistema agrossilvipastoril, no momento do plantio das mudas, com $80 \mathrm{~kg} \mathrm{ha}^{-1}$ de NPK.

Para a análise financeira, foram simulados dois cenários para o produto final da floresta. No primeiro simulou-se uma rotação de 10 anos com produto destinado para lenha, e uma rotação de 15 anos com produto destinado para serraria. No segundo cenário, simulouse um desbaste aos 10 anos para lenha, permanecendo 250 ind ha ${ }^{-1}$ destinados para serraria aos 15 anos. Os produtores na região costumam comercializar a lenha por $\mathrm{R} \$ 25,00$ o metro estéreo (st) e $\mathrm{R} \$ 100,00 \mathrm{~m}^{-3}$ para serraria. 
Tabela 4. Custo de implantação do plantio florestal e do sistema agrossilvipastoril, em Nova Esperança do Sul, RS.

\begin{tabular}{|c|c|c|}
\hline Descrição & Plantio florestal & $\begin{array}{c}\text { Sistema } \\
\text { agrossilvipastoril }\end{array}$ \\
\hline \multicolumn{3}{|c|}{ Preparo da área } \\
\hline $\begin{array}{l}\text { Serviço do operador de } \\
\text { máquina }\end{array}$ & $\mathrm{R} \$ 37,50$ & $\mathrm{R} \$ 25,00$ \\
\hline \multicolumn{3}{|c|}{ Insumos } \\
\hline Mudas: Eucalyptus sp. & $\mathrm{R} \$ 377,19$ & $\mathrm{R} \$ 247,50$ \\
\hline Mudas: Acacia mearnsii & $\mathrm{R} \$ 82,97$ & - \\
\hline Calcário & - & $\mathrm{R} \$ 58,50$ \\
\hline Adubo NPK & - & $\mathrm{R} \$ 162,00$ \\
\hline Fosfato natural e/ou ureia & - & $\mathrm{R} \$ 291,60$ \\
\hline Formicida granulado & - & $\mathrm{R} \$ 72,00$ \\
\hline Inseticida & $\mathrm{R} \$ 54,00$ & $\mathrm{R} \$ 270,00$ \\
\hline Herbicida & $\mathrm{R} \$ 50,40$ & $\mathrm{R} \$ 50,40$ \\
\hline Máquina de operação & $\mathrm{R} \$ 300,00$ & $\mathrm{R} \$ 200,00$ \\
\hline \multicolumn{3}{|c|}{ Mão de obra } \\
\hline $\begin{array}{c}\text { Aplicação inseticida e } \\
\text { herbicida }\end{array}$ & $\mathrm{R} \$ 50,00$ & $\mathrm{R} \$ 6,25$ \\
\hline Plantio, replantio, adubação & $\mathrm{R} \$ 350,00$ & $\mathrm{R} \$ 200,00$ \\
\hline Controle de formiga & $\mathrm{R} \$ 50,00$ & $\mathrm{R} \$ 25,00$ \\
\hline Calagem & - & $\mathrm{R} \$ 18,75$ \\
\hline Coroamento & $\mathrm{R} \$ 75,00$ & $\mathrm{R} \$ 75,00$ \\
\hline Custo total & $\mathrm{R} \$ 1.427,06$ & $\mathrm{R} \$ 1.702,00$ \\
\hline
\end{tabular}

Para verificar a viabilidade financeira do plantio florestal e do sistema agrossilvipastoril, foram utilizados os seguintes critérios: valor presente líquido (VPL), valor anual equivalente (VAE), taxa interna de retorno (TIR), razão benefício-custo $(\mathrm{B} / \mathrm{C})$, custo médio de produção (CMPr) (equações 1 a 5, respectivamente) e análise de sensibilidade, por meio de diferentes taxas de desconto.
VPL $=\sum_{i=0}^{n} R_{i}(1+i)^{-j}-\sum_{i=0}^{n} C j(1+i)^{-j} \quad 1$

$\mathrm{VAE}=\frac{\mathrm{VPL}_{-i} \cdot(1+\mathrm{i})^{\mathrm{nt}}}{(1+\mathrm{i})^{\mathrm{nt}}-1}$

TIR $=\sum_{j=0}^{n} R_{j}(1+i)^{-j}-\sum_{j=0}^{n} C_{j}(1+i)^{-j}=0 \quad 3$

$\mathrm{B} / \mathrm{C}=\frac{\sum_{j=0}^{n} R_{j}(1+i)^{-j}}{\sum_{j=0}^{n} c_{j}(1+i)^{-j}}$

$\operatorname{CMPr}=\frac{\sum_{j 0}^{n} C T_{j}}{\sum_{j=0}^{n} Q T_{j}}$

Em que: $\mathrm{VPL}=$ valor presente líquido; $\mathrm{VAE}=$ valor anual equivalente; TIR = taxa interna de retorno; $\mathrm{B} / \mathrm{C}=$ razão benefício-custo; $\mathrm{CMPr}=$ custo médio de produção. $\mathrm{C}_{\mathrm{j}}=$ custo no final do ano $j ; R_{j}=$ receita no final do ano $j ; i=$ taxa de desconto; $\mathrm{n}=$ duração do projeto em anos; $\mathrm{CT}_{\mathrm{j}}=$ custo total atualizado; $\mathrm{QT}_{\mathrm{j}}=$ produção total equivalente; $\mathrm{t}=$ número de períodos de capitalização.

\section{Resultados e discussão}

O incremento médio anual (IMA) no plantio florestal foi mais elevado (27,7\%), quando comparado ao sistema agrossilvipastoril. Isso se deve ao maior número de árv. ha $^{-1}$. Porém, o incremento médio individual por ano do sistema agrossilvipastoril foi mais elevado $(21,9 \%)$. O maior incremento individual das plantas (inc) no sistema agrossilvipastoril pode ser em resposta à adubação utilizada.

O replantio das mudas de eucalipto e acácia-negra foi realizado utilizando uma estimativa de perdas de aproximadamente $10 \%$, sendo este valor acrescido sobre a densidade inicial de plantio.

Os valores para cada critério financeiro referente aos dois sistemas de produção florestal estão apresentados na Tabela 5.

O plantio florestal apresentou maior valor presente líquido (VPL) nas rotações de 10 e 15 anos, quando comparado ao VPL do sistema agrossilvipastoril (Tabela 5). O VPL maior para o plantio convencional se deve ao maior número de indivíduos na área (Tabela 3). 
Tabela 5. Indicadores financeiros para o plantio florestal e o sistema agrossilvipastoril para a rotação de 10 e 15 anos, em Nova Esperança do Sul, RS.

\begin{tabular}{|c|c|c|c|c|c|c|}
\hline Rotação & Componente florestal & $\begin{array}{c}\text { VPL } \\
\left(\mathrm{RS} \mathrm{ha}^{-1}\right)\end{array}$ & $\begin{array}{c}\text { VAE } \\
\left(\mathrm{R} \text { ha }^{-1} \mathbf{a n o}^{-1}\right)\end{array}$ & $\begin{array}{c}\text { TIR } \\
\text { (\% a.a.) }\end{array}$ & $\mathrm{B} / \mathrm{C}$ & $\begin{array}{c}\text { CMPr } \\
\left(\mathrm{R} \$ \mathrm{~m}^{-3}\right)\end{array}$ \\
\hline \multirow{2}{*}{10 anos } & Plantio florestal & $8.042,24$ & $1.171,64$ & 31,68 & 6,04 & 5,18 \\
\hline & Sistema Agrossilvipastoril & $4.561,95$ & 664,61 & 22,60 & 3,44 & 7,27 \\
\hline \multirow{2}{*}{15 anos } & Plantio florestal & $12.951,24$ & $1.467,21$ & 31,86 & 9,12 & 7,29 \\
\hline & Sistema Agrossilvipastoril & $10.848,88$ & $1.229,04$ & 24,83 & 6,80 & 10,15 \\
\hline
\end{tabular}

Em que: $\mathrm{VPL}=$ valor presente líquido; $\mathrm{VAE}=$ valor anual equivalente; $\mathrm{TIR}=$ taxa interna de retorno; $\mathrm{B} / \mathrm{C}=$ razão benefício/custo; $\mathrm{CMPr}=$ custo médio de produção.

O sistema agrossilvipastoril apresentou menor VPL devido ao menor número de indivíduos. No entanto, esses sistemas apresentam vantagens, quando comparados a plantios florestaia, por ser um sistema produtivo que combina proteção ambiental com uso eficiente da terra (Nicodemo et al., 2016); por minimizar a lixiviação de nutrientes das plantas e do solo; as espécies florestais participam da ciclagem de nutrientes, favorecendo a melhoria da estrutura do solo (Silva et al., 2013); na criação de animais com acesso à sombra, que tem mostrado excelentes resultados por melhorar o rendimento econômico das propriedades (Botero, 2001), além de vantagem direta para o produtor, é a viabilidade econômica e melhoria na qualidade pela diversificação da produção (Silva, 2013; Santos \& Paiva, 2002; Abdo et al., 2008; Liberali, 2013).

Segundo Silva \& Farias (2015) o valor anual equivalente (VAE) é definido como a parcela periódica e constante do VPL. O VAE permite comparar projetos com horizontes de planejamento diferentes, sendo o mais lucrativo àquele de maior VAE. O plantio florestal apresentou maior valor em relação ao sistema agrossilvipastoril para as duas rotações simuladas (tabela 5). Foi possível constatar que ambos os plantios apresentaram maior VAE para a rotação de 15 anos, quando o produto final é destinado para serraria.

A confiabilidade financeira dos plantios foi verificada pela taxa interna de retorno (TIR), quando essa foi maior que a taxa de desconto de 7,5\% a.a. Segundo Rezende \& Oliveira (2008), a TIR refere-se à taxa anual de retorno do capital investido. Nesse estudo foi possível perceber que o sistema agrossilvipastoril apresentou menor TIR e a rotação de 15 anos foi mais viável economicamente do que a rotação de 10 para ambos os plantios.

A razão benefício-custo, que determina a relação entre o valor presente dos benefícios e o valor presente dos custos para uma determinada taxa de juros, comprova o retorno financeiro do plantio florestal e do sistema agrossilvipastoril para ambas as rotações $(6,04$ e 3,44 para 10 anos, e 9,12 e 6,80 para 15 anos, respectivamente), comprovando maior retorno na rotação de 15 anos e no plantio convencional, corroborando o que os outros indicadores apontaram anteriormente.

O CMPr representa o preço mínimo para que o produto seja comercializado, independente da quantidade produzida e do tempo de duração do investimento, para que o VPL seja igualado a zero. O plantio florestal apresentou menor custo de produção em relação ao sistema agrossilvipastoril e maior custo para a rotação de 15 anos.

Pela análise de sensibilidade, que considera a variação nas taxas de juros, é possível verificar até que ponto as oscilações podem influenciar de forma positiva ou negativa os sistemas agrossilvipastoris. Ou seja, considerando que a taxa de juros remunera o investimento, os cenários com taxas mais elevadas tornam o projeto menos atrativo, subsidiando a tomada de decisão em investir ou não nesse tipo de empreendimento.

Esses cenários construídos estão apresentados na Figura 2. Os resultados apontam que a medida que aumenta a taxa de desconto, o VPL diminui. Apesar do comportamento do VPL em relação à taxa de juro ser semelhante, os sistemas apresentam diferentes VPL para uma mesma taxa, podendo ser viável ou inviável em diferentes situações, devido ao custo de implantação, manutenção e receitas oriundas de cada sistema.

Constatou-se que os dois povoamentos apresentaram uma taxa de segurança para as rotações de 10 e 15 anos, ou seja, maior que a taxa de juros utilizada $(7,5 \%$ ao ano), oferecendo maior segurança e incentivando a continuidade de investimento nesse tipo de empreendimento. 
A)

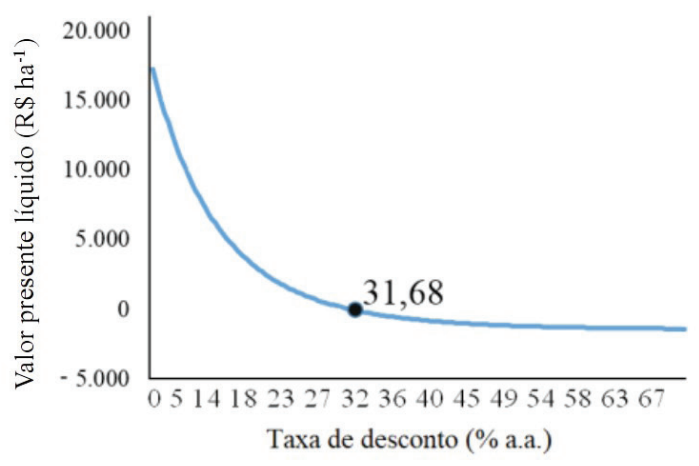

C)

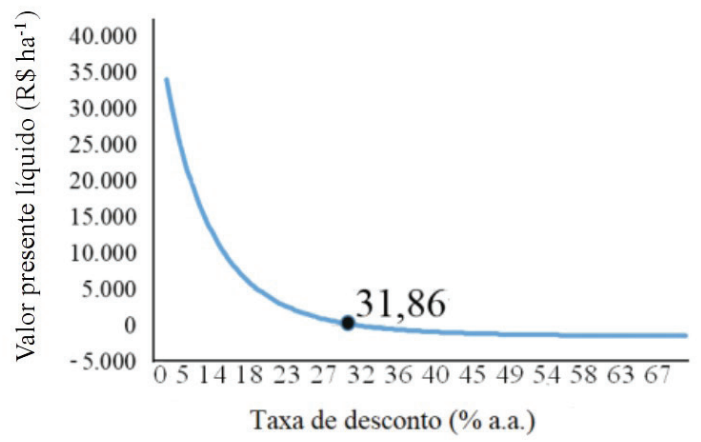

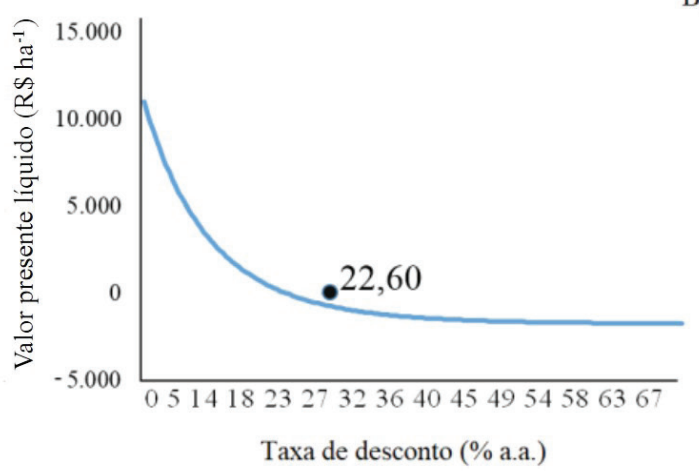

D)

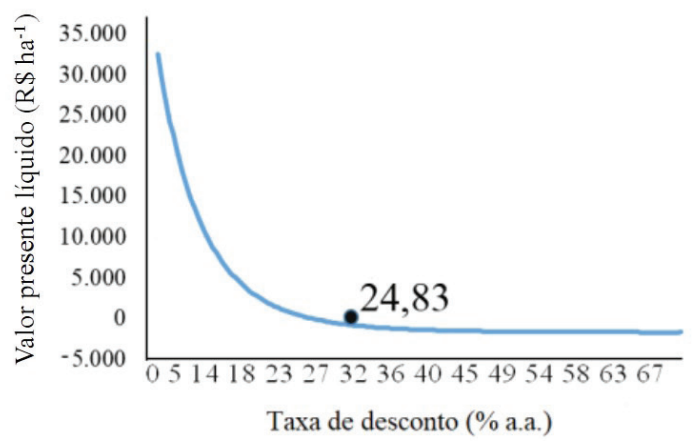

Figura 2. Análise de sensibilidade do valor presente líquido $\left(\mathrm{R} \$ \mathrm{ha}^{-1}\right)$ em relação a taxa de desconto (\% a. a.) para o plantio florestal (A e C) e sistema agrossilvipastoril (B e D) para as rotações de 10 (A e B) e 15 anos (C e D).

Também foi possível constatar que a venda de lenha como produto final foi atrativa para a rotação de 10 anos. Porém, essa atratividade foi melhor para a rotação de 15 anos, pois apresentou melhor retorno pelo produto final (tora) ser mais valorizado, com melhor valor agregado.

A viabilidade econômica e sustentável de sistemas agroflorestais, quando comparada aos plantios convencionais, auxilia na conservação do meio ambiente, em áreas que não apresentam sinais de degradação e, principalmente, naquelas áreas sujeitas à degradação, proporcionando maior estabilidade econômica, social e ambiental. Esses fatores justificam estudos que visem identificar as potencialidades econômicas e os benefícios ambientais gerados pelos sistemas (ArcoVerde, 2008; Radomski \& Ribaski, 2009). Esses sistemas implementados em pequenas propriedades possibilitam o fortalecimento da agricultura familiar, a partir de manejos adequados, e de culturas apropriadas a cada região, colaborando para o aumento da renda ou produção daquela localidade, tornando atrativo o campo e a sua exploração (Moreira \& Binotto, 2014).

\section{Conclusões}

Os plantios florestais são mais viáveis economicamente, que os sistemas agroflorestais, quando comparado apenas o componente florestal. Porém, os sistemas agrossilvipastoris, além de serem viáveis economicamente, são também uma alternativa de renda para os pequenos produtores rurais, pois além de produtos oriundos da silvicultura contam com a diversificação da produção com agricultura e pecuária, além dos benefícios ambientais.

\section{Referências}

Abdo, M. T. V. N. et al. Sistemas agroflorestais e agricultura familiar: uma parceria interessante. Revista Tecnologia \& Inovação Agropecuária, p. 50-59, dez. 2008. 
Arco-Verde, M. F. Sustentabilidade biofísica e socioeconômica de sistemas agroflorestais na Amazônia Brasileira. 2008. Tese (Doutorado em Ciências Florestais) - Universidade Federal do Paraná, Curitiba.

Banco Nacional de Desenvolvimento Econômico e Social. Programa ABC. Disponível em: < https://www.bndes.gov.br/wps/portal/site/ home/financiamento/produto/programa-abc $>$. Acesso em: 12 nov. 2015 .

Bentes-Gama, M. M. et al. Análise econômica de sistemas agroflorestais na Amazônia Ocidental, Machadinho d'Oeste - RO. Revista Árvore, v. 29, n. 3, p. 401-411, 2005.

Botero, J. A. Contribuição dos sistemas pecuários tropicais na captação de carbono. In: Carvalho, M. M. et al. (Ed.). Sistemas agroflorestais pecuários: opções de sustentabilidade para áreas tropicais e subtropicais. Juiz de Fora: Embrapa Gado de Leite; Brasília: FAO, 2001. p. 399-413.

Ferraz, J. M. G. As dimensões da sustentabilidade e seus indicadores. In: Marques, J. F. et al. (Ed.). Indicadores de sustentabilidade em agroecossistemas. Jaguariúna: Embrapa Meio Ambiente, 2003. 281 p. Parte I, cap.1, p. 15-35.

Liberali, L. Sistemas agroflorestais: alternativa de renda para agricultura familiar do Município de Corumbataí do Sul - Paraná.

Revista Geomae, v. 4, n. 1, p. 58-69, 2013.

Loetsch, F. et al. Forest inventory. 2. ed. Munich: BLV Verlagsgesellschaft, 1973. v. 2. 469 p.

Moreira, F. G. \& Binotto, E. A diversificação de culturas agronômicas como forma sustentável na agricultura familiar: uma análise para o estado/MS. Revista Verde, v. 9, n. 5, p. 68-75, 2014.
Moreno, J. A. Clima do Rio Grande do Sul. Porto Alegre: Secretaria da Agricultura, 1961. $42 \mathrm{p}$.

Nicodemo, M. L. F. Growth of nativa trees in two agroforestry systems. Revista Árvore, v. 40, n. 4, p. 639-648, 2016. DOI: 10.1590/0100-67622016000400007.

Radomski, M. I. \& Ribaski, J. Sistemas silvipastoris: aspectos da pesquisa com eucalipto e grevílea nas regiões sul e sudeste do Brasil. Colombo: Embrapa Florestas, 2009. (Embrapa Florestas. Documentos, 191).

Rezende, J. L. P. \& Oliveira, A. D. Análise econômica e social de projetos florestais. 2. ed. Viçosa: Ed da UFV, 2008. 386 p.

Roberto, J. V. B. \& Souza, B. B. Fatores ambientais, nutricionais e de manejo e índices de conforto térmico na produção de ruminantes no semiárido. Revista Verde, v. 6, n. 2, p. 8-13, 2011.

Santos, M. J. C. \& Paiva, S. N. Os sistemas agroflorestais como alternativa econômica em pequenas propriedades rurais: estudo de caso. Ciência Florestal, v. 12, n. 1, p. 135-141, 2002.

Silva, D. P. SAFs: sistemas alternativos de produção. Revista de Extensão e Estudos Rurais, v. 2, n. 1, p. 153-162, 2013.

Silva, F. C. L. da \& Farias, J. A. de. Análise econômica da produção de Acacia mearnsii De Wild e carvão vegetal no Vale do Caí e Taquari, Rio Grande do Sul. Ciência Rural, v. 45, n. 5, p. 927-932, 2015. DOI: $10.1590 / 0103-8478 \mathrm{cr} 20140114$.

Streck, E. V. et al. Solos do Rio Grande do Sul. 2. ed. Porto Alegre: EMATER/RS, 2008. p. 38-54.

Thevathasan, N. Sustainability indicators of biomass production in agroforestry systems. The Open Agriculture Journal, v. 8, p. 1-11, 2014. 